\title{
Prospective validation of the diagnostic score for molecular analysis of hereditary autoinflammatory syndromes in Italian children with periodic fever
}

\author{
S Federici ${ }^{* 1,8}$, F Caroli ${ }^{2}$, MP Sormani ${ }^{3}$, A Meini ${ }^{4}$, R Caorsi ${ }^{1}$, G Martini ${ }^{5}$, \\ G Simonini ${ }^{6}$, R Consolini ${ }^{7}$, S Plebani ${ }^{4}$, M Baldi ${ }^{7}$, I Ceccherini ${ }^{2}$, A Martini ${ }^{1}$ \\ and $\mathrm{M}$ Gattorno ${ }^{1}$
}

Address: ${ }^{1}$ UO Pediatria II Istituto G. Gaslini and Dipartimento di Pediatria, University of Genoa, Genoa, Italy, ${ }^{2}$ Laboratorio di Genetica Molecolare, Istituto G. Gaslini, Genoa, Italy, ${ }^{3}$ Unità di Biostatistica, DISSAL, University of Genoa, Genoa, Italy, ${ }^{4}$ Dipartimento di Pediatria, Unità di Immunologia e Reumatologia Pediatrica, Spedali Civili e University of Brescia, Brescia, Italy, ${ }^{5}$ Dipartimento A.I. di Pediatria, University of Padua, Padova, Italy, ${ }^{6}$ UO Reumatologia Pediatrica, Ospedale Meyer, Firenze, Italy, ${ }^{7}$ Department of Pediatrics and Reproductive Medicine, University of Pisa, Pisa, Italy and ${ }^{8}$ Dipartmento di Genetica Umana, Ospedale Galliera, Genoa, Italy

* Corresponding author

from 15th Paediatric Rheumatology European Society (PreS) Congress

London, UK. 14-17 September 2008

Published: 15 September 2008

Pediatric Rheumatology 2008, 6(Suppl I):PI78 doi:10.II86/I546-0096-6-SI-PI78

This abstract is available from: http://www.ped-rheum.com/content/6/SI/PI78

(c) 2008 Federici et al; licensee BioMed Central Ltd.

\section{Objective}

Aim of the study was to verify in a prospective study the sensitivity and specificity of a recently elaborated diagnostic score for the prediction of the presence of mutation of genes associated with periodic fever [1].

\section{Patients and methods}

Detailed clinical information of 100 Italian patients with a clinical history of periodic fever was collected since June 2007. For each patient the Diagnostic score (www.printo.it/periodicfever) was calculated. According to previous experiences a cut-off $>1.32$ was chosen to define those patients at high risk to carry relevant mutations. All patients were screened for mutations of $M V K$, TNFRSF1A and MEFV genes.

\section{Results}

Ten patients displayed relevant (homozygous or compound heterozygous) mutations for MVK and MEFV genes. No structural mutations of TNFRSF1A gene were found. 10 patients dysplayed low-penetrance mutations of the TNFRSF1A gene (R92Q) or a single mutation of the MEFV gene. 80 patients were negative to all the three genes.
The Diagnostic score revealed high sensitivity (90\%) and specificity (65\%) in discriminating positive and negative patients. The regression tree analysis [1] was able to provide the correct identification of the affected gene in 7 out of the 9 positive identified by the diagnostic score.

\section{Conclusion}

This study confirm the validity of the Diagnostic score as a useful tool for the identification of children at higher risk to carry relevant mutations of genes associated with periodic fever.

\section{References}

I. Gattorno M, et al:: A diagnostic score for molecular analysis of hereditary autoinflammatory syndromes with periodic fever in children. Arthritis Rheum 2008, 58:1823-1832. 